\title{
Fe-Mn binary oxide incorporated into diatomite as an adsorbent for arsenite removal: Preparation and evaluation
}

\author{
Fangfang Chang ${ }^{\mathrm{a}, \mathrm{b}}$, Jiuhui $\mathrm{Qu}^{\mathrm{a}, *}$, Huijuan Liu ${ }^{\mathrm{a}}$, Ruiping $\mathrm{Liu}^{\mathrm{a}}, \mathrm{Xu}$ Zhao ${ }^{\mathrm{a}}$ \\ a State Key Laboratory of Environmental Aquatic Chemistry, Research Center for Eco-Environmental Sciences, Chinese Academy of Sciences, Beijing 100085, China \\ ${ }^{\mathrm{b}}$ Graduate School of Chinese Academy of Sciences, Beijing 100039, China
}

\section{A R T I C L E I N F O}

\section{Article history:}

Received 16 March 2009

Accepted 16 June 2009

Available online 26 June 2009

\section{Keywords:}

Arsenite

Fe-Mn binary oxide

Diatomite

Adsorption

Oxidation

\begin{abstract}
A B S T R A C T
Fe-Mn binary oxide incorporated into diatomite (FMBO-diatomite) was prepared by a simple coating method, and exhibited high oxidation and adsorption ability for arsenite [As(III)]. After being incorporated by $\mathrm{Fe}-\mathrm{Mn}$ binary oxide, the surface area of diatomite increased 36\%, and the pore volume increased five times. The $\mathrm{pH}_{\mathrm{zpc}}$ of FMBO-diatomite was determined to be 8.1. These characteristics are responsible for the increased $\mathrm{As}$ (III) adsorption efficiency. The adsorption equilibria of $\mathrm{As}$ (III) on FMBO-diatomite were described well by a Langmuir isotherm model due to the homogeneous distribution of Fe-Mn binary oxide on a diatomite surface. $\mathrm{As}(\mathrm{III})$ was oxidized into $\mathrm{As}(\mathrm{V})$, and then adsorbed by FMBO-diatomite. The oxidation and adsorption efficiencies for As(III) depended deeply on the $\mathrm{pH}$ of solution. When the $\mathrm{pH}$ was raised to 8.1, the As(III) adsorption efficiency of FMBO-diatomite was almost equal to the As(III) oxidation efficiency. Silicate and phosphate had negative effects on As(III) adsorption. Also the influence of silicate and phosphate with the $\mathrm{pH}$ variation was different.
\end{abstract}

(c) 2009 Elsevier Inc. All rights reserved.

\section{Introduction}

Arsenic, as a carcinogenic substance, is present mostly as arsenite $[\mathrm{As}(\mathrm{III})]$ and arsenate $[\mathrm{As}(\mathrm{V})]$ in natural water $[1]$. $\mathrm{As}(\mathrm{III})$ is more mobile and toxic than $\mathrm{As}(\mathrm{V})$ [2,3]. Therefore, efficient removal of As(III) is more desired.

Being different from other arsenic removal techniques, adsorption seems to be a promising route to effectively and economically remove As(III) with metal-oxide adsorbents [4,5]. Among these adsorbents, $\mathrm{Fe}-\mathrm{Mn}$-based adsorbents have played a dominant role in the removal of As(III). A low-cost ferruginous manganese ore can remove $\mathrm{As}(\mathrm{III})$ from groundwater without any preoxidation [6]. Mn-substituted iron oxyhydroxide was prepared by the oxidation of ferrous carbonate, and exhibited high removal efficiency for As(III) [7]. However, applications of these Fe-Mn-based adsorbents were complicated in large-scale treatments. Ferruginous manganese ore had low adsorption capacity, because the ore crystal has a small amount of adsorption sites. Mn-substituted iron oxyhydroxide had low hydraulic conductivity, because this adsorbent was an amorphous material.

As a porous supporting material, diatomite has various good characteristics, i.e., high permeability, high porosity, and low bulk density [8]. In water treatment, diatomite was modified by Mn oxides to increase the surface area for adsorbing lead and dye $[9,10]$. Fe (25\%)-diatomite exhibited high adsorption speed for arsenic

\footnotetext{
* Corresponding author. Fax: +86 1062923558

E-mail address: jhqu@rcees.ac.cn (J. Qu).
}

[11], due to the well-dispersed hydrous ferric oxide on the diatomite.

In this study, Fe-Mn binary oxide was incorporated into diatomite (FMBO-diatomite) by a simple coating method. After being dried, the granular FMBO-diatomite was used as an absorbent in the removal of $\mathrm{As}(\mathrm{III})$. The strong oxidation and adsorption abilities of FMBO-diatomite were determined through batch equilibration experiments. Effects of temperature, $\mathrm{pH}$, and coexisting anions on the As(III) adsorption efficiency were also studied.

\section{Material and methods}

\subsection{Materials}

All chemicals were analytical grade from Beijing Chemical Reagents Company. Stock solutions of As(III) were prepared by dissolving $\mathrm{NaAsO}_{2}$ with deionized water. The $\mathrm{NaNO}_{3}, \mathrm{HNO}_{3}$, and $\mathrm{NaOH}$ solutions, used in the titration experiments, were prepared with ultrapure water. Other chemicals and reagents were dissolved or diluted by deionized water. The glassware was cleaned by washing with tap water, soaked with $10 \% \mathrm{HNO}_{3}$ for at least $24 \mathrm{~h}$, and finally rinsed with deionized water for three times.

Diatomite, from Changbai Mountain in China, mainly consists of silicon dioxide $(\geqslant 85 \%, \mathrm{w} / \mathrm{w})$. The diatomite was washed with tap water to remove fines and other adhered impurities and then dried at $60{ }^{\circ} \mathrm{C}$ for $24 \mathrm{~h}$. The dried diatomite was sieved to a uniform size of $0.25-0.35 \mathrm{~mm}$, and stored in polyethylene bottles. 


\subsection{Incorporation of $\mathrm{Fe}-\mathrm{Mn}$ binary oxide into diatomite}

A precursor of Fe-Mn binary oxide was prepared by $150 \mathrm{~mL}$ solution of $\mathrm{FeSO}_{4} \cdot 7 \mathrm{H}_{2} \mathrm{O}(0.075 \mathrm{~mol} / \mathrm{L})$ and $\mathrm{KMnO}_{4}(0.025 \mathrm{~mol} / \mathrm{L})$. The following procedure was developed to incorporate Fe-Mn binary oxide precursor into pores of diatomite as homogeneously as possible: (1) Place $50 \mathrm{~g}$ of dried diatomite into $75 \mathrm{~mL}$ solution of $\mathrm{FeSO}_{4}(0.075 \mathrm{~mol} / \mathrm{L})$. (2) Add $75 \mathrm{~mL}$ solution of $\mathrm{KMnO}_{4}$ $(0.025 \mathrm{~mol} / \mathrm{L})$ and $\mathrm{NaOH}(0.1 \mathrm{~mol} / \mathrm{L})$ into the above solution. (3) Stir the suspension liquid gently for $30 \mathrm{~min}$ at $\mathrm{pH}$ of 4.5-5.0. (4) Separate the solids from the suspension and dry the solids at $60{ }^{\circ} \mathrm{C}$ for $12 \mathrm{~h}$. A homogeneous load of Fe-Mn binary oxide was judged by observing the change of deep brown color distribution on the diatomite. The adsorbent FMBO-diatomite, deep brown grain (size of $0.25-0.35 \mathrm{~mm}$ ), was prepared and stored in polyethylene bottles for the subsequent experiments.

\subsection{Adsorbent characterization}

The surface morphologies of diatomite and FMBO-diatomite were examined by scanning electron microscopy (SEM) (S3000 N, Hitachi Co., Japan) with energy-dispersive X-ray analysis (EDX) (EDAX Co., USA). FTIR spectra were collected on a Nicolet 5700 FTIR spectrophotometer (Nicolet Co., USA) using a transmission model. Samples for FTIR determination were ground with spectral grade $\mathrm{KBr}$ in an agate mortar. IR spectra of diatomite and FMBO-diatomite were obtained as dry samples in $\mathrm{KBr}$ pellets corresponding to $5 \mathrm{mg}$ of sample in approximately $100 \mathrm{mg}$ of spectral grade $\mathrm{KBr}$. All IR measurements were carried out at room temperature. Both the second derivative and the deconvoluted spectra were used to determine the number of overlapping bands. Then, Gaussian profile fitting was performed to reveal the assemblage of multiple bands using the Jandel PeakFit software (PeakFit-Jandel Scientific Software, San Rafael, CA).

The specific surface area and average pore size distribution of diatomite and FMBO-diatomite were measured by the nitrogen adsorption-desorption isotherm method using the accelerated surface area and porosimetry (ASAP 2000, Micromeritics Co., USA). The amount of Fe and $\mathrm{Mn}$ in $1.0 \mathrm{~g}$ FMBO-diatomite was determined by digesting via $40 \mathrm{~mL} 98 \%$ nitric acid. The acidic solution was filtered through a $0.45-\mu \mathrm{m}$ membrane filter and analyzed for Fe and Mn concentration. Potentiometric titrations of FMBO-diatomite were conducted using an automatic potentiometric titrator (716 DMS, Metrohm Co., Switzerland) at $25^{\circ} \mathrm{C}$ in $0.1,0.01$, and $0.001 \mathrm{~mol} / \mathrm{L} \mathrm{NaNO}_{3}$ solutions, respectively. The prepared suspensions (solid concentration $1.0 \mathrm{~g} / \mathrm{L}$ ) were equilibrated at the desired ionic strength for $24 \mathrm{~h}$. In the whole titration procedure, two steps were performed. The suspensions were acidified to $\mathrm{pH} 2.5$ in acidimetric titration first, and then back titrated to the alkaline region in alkalimetric titration, purging with $\mathrm{N}_{2}$ gas to minimize $\mathrm{CO}_{2}$ contamination. The titrants were $0.05 \mathrm{~mol} / \mathrm{L} \mathrm{NaOH}$ and $0.05 \mathrm{~mol} / \mathrm{L}$ $\mathrm{HNO}_{3}$.

\subsection{Batch adsorption experiments}

The isotherm experiments were conducted to evaluate adsorption capacities of As(III) at constant temperatures of $10,25,35$, and $45^{\circ} \mathrm{C}$ with a pH of 5.0 or 7.0. The other adsorption conditions were $1.0 \mathrm{~g} / \mathrm{L}$ FMBO-diatomite, initial As(III) concentration of 0.05$5.0 \mathrm{mg} / \mathrm{L}$, and $24 \mathrm{~h}$ equilibrium time.

To investigate the influence of initial $\mathrm{pH}(2.0-11.0)$ on the oxidation and adsorption efficiency for As(III), the experiments were performed with $1.0 \mathrm{~g} / \mathrm{L}$ FMBO-diatomite and $1.0 \mathrm{mg} / \mathrm{L} \mathrm{As}$ (III) solutions for $6.0 \mathrm{~h}$ of equilibrium time at $25^{\circ} \mathrm{C}$.

The effects of common coexisting anions in water, i.e., carbonate, sulfate, fluoride, nitrate, silicate, and phosphate, were investi- gated by adding a defined amount $(1.0 \mathrm{~g} / \mathrm{L})$ of FMBO-diatomite into one solution which contained $1.0 \mathrm{mmol} / \mathrm{L}$ of the coexisting anions and $1.0 \mathrm{mg} / \mathrm{L}$ of $\mathrm{As}(\mathrm{III})$. The vessels were shaken for $6.0 \mathrm{~h}$ at $25^{\circ} \mathrm{C}$. The solution $\mathrm{pH}$ values were adjusted to $3.5,6.0$, and 9.0.

All batch solutions were sampled and filtered through $0.45-\mu \mathrm{m}$ membrane filter, and then analyzed for arsenic [As(tot)] and As(III). The analysis of As(III) was finished within $30 \mathrm{~min}$ in order to avoid air oxidation.

\subsection{Analytical methods}

Inductively coupled plasma optical emission spectrometry (ICPOES) (Optima 2000, PerkinElmer Co., USA) was used for As(tot), Fe, and $\mathrm{Mn}$ concentrations. Hydride generation atomic fluorescence spectrometry (HG-AFS) (Beijing Beifenruili Analytic Instrument Co., China) was used for $\mathrm{As}(\mathrm{III})$ concentrations. The $\mathrm{pH}$ of solution was adjusted by adding $0.1 \mathrm{~mol} / \mathrm{L} \mathrm{HNO}_{3}$ or $0.1 \mathrm{~mol} / \mathrm{L} \mathrm{NaOH}$, and was measured with a $\mathrm{pH}$ meter (Model 720A, Orion Co., USA).

\subsection{Quality assurance}

In order to ascertain reliability, accuracy, and reproducibility of the experiment data, the batch adsorption experiments were replicated twice and experimental blanks were run in parallel. Sample blanks were analyzed for the correction of background effect on instrument response. For analytical calibration standard, solutions with arsenic concentrations ranging from 0 to $5.0 \mathrm{mg} / \mathrm{L}$ were employed on ICP-OES. Calibration curves between 0 and $0.5 \mathrm{mg} / \mathrm{L}$ As(III) were prepared for HG-AFS. The limits of determinations on ICP-OES and HG-AFS were 0.040 and $0.0005 \mathrm{mg} / \mathrm{L}$, respectively. Precision of the parallel measurements was $\pm 5 \%$ RSD (relative standard deviation). The software Origin 7.5 was used to deal with all experiment data in this study.

\section{Results and discussion}

\subsection{Characterization of FMBO-diatomite}

\subsubsection{SEM with EDX analysis}

The morphologies of diatomite and FMBO-diatomite are displayed in Fig. 1. Many pores can be seen on the surface of diatomite (Fig. 1a). After being incorporated, the surface of diatomite was covered by Fe-Mn binary oxide, and a porous structure can still be observed (Fig. 1b), which is beneficial for the As(III) adsorption. Compared to amorphous Fe-Mn binary oxide described in our previous work [12], FMBO-diatomite exhibited higher mechanical strength and higher water permeability. As shown in the EDX elemental analysis (Fig. 1c and d), silicon was the main element in diatomite and FMBO-diatomite. The chemical composition of FMBO-diatomite showed that the elemental molar ratio of Fe to Mn was 3:1, the same as that of the preparation precursor.

\subsubsection{FTIR spectroscopy fitting}

The FTIR spectra of diatomite and FMBO-diatomite are presented in Fig. 2. The overlapping bands were fitted via the Peakfit software. Fitting correlation coefficients $\left(r^{2}\right)$ of diatomite and FMBO-diatomite FTIR spectra are 0.9452 and 0.9486 , respectively. In Fig. 2a, the resolved band positions are illustrated at approximately $1280,1200,1090,990,790,615$, and $475 \mathrm{~cm}^{-1}$ (Fig. 2a), which are attributed to the infrared characteristic peaks of diatomite [13]. When diatomite was loaded by Fe-Mn binary oxide, the intensities of these bands decreased (Fig. 2b). Compared to diatomite, three new bands at 1378, 711, and $535 \mathrm{~cm}^{-1}$ were observed in FTIR spectra of FMBO-diatomite. The vibration at $535 \mathrm{~cm}^{-1}$ may be attributed to either the asymmetric $\mathrm{Fe}-\mathrm{O}$ 

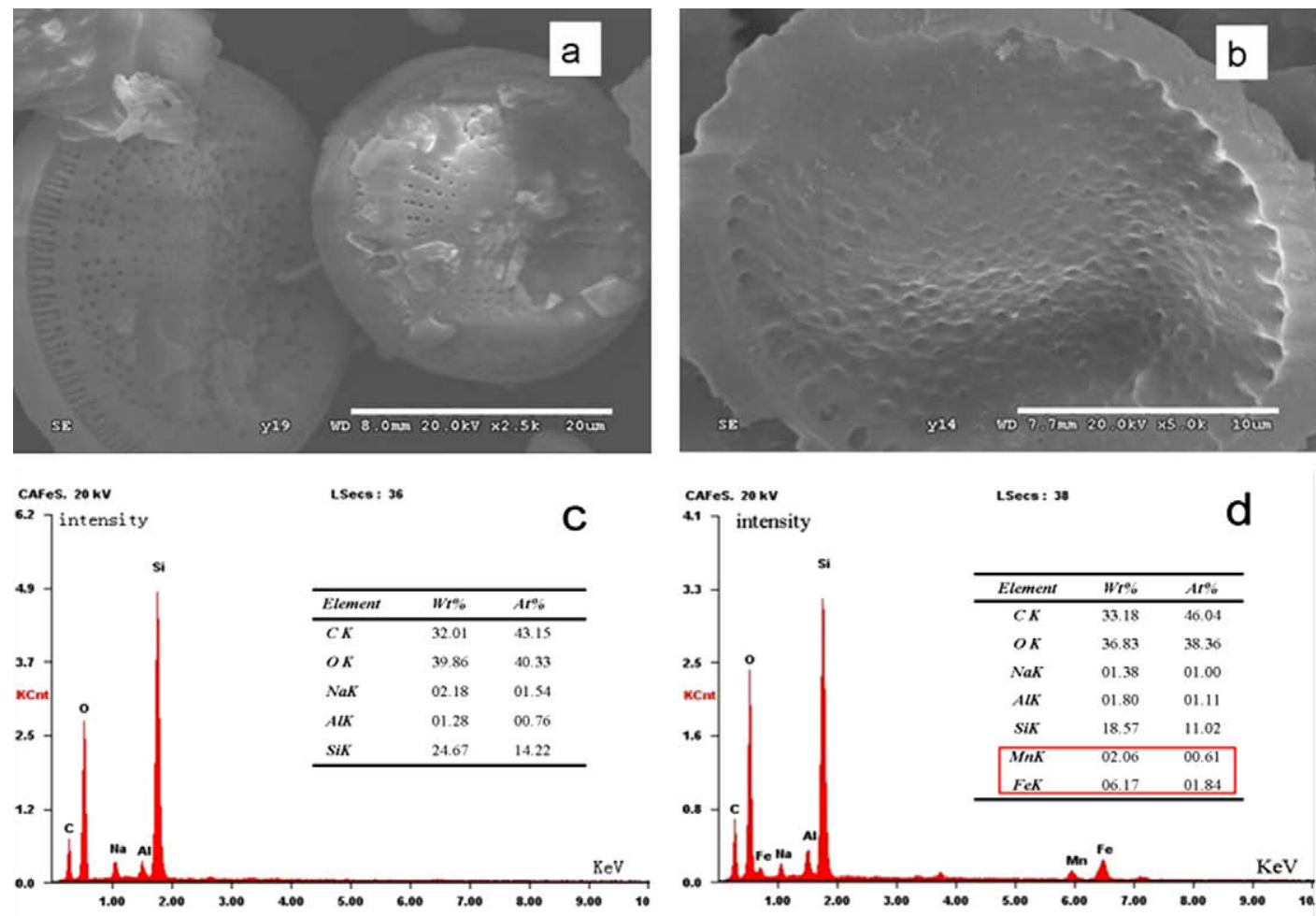

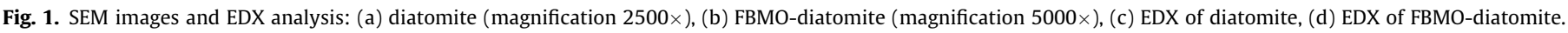
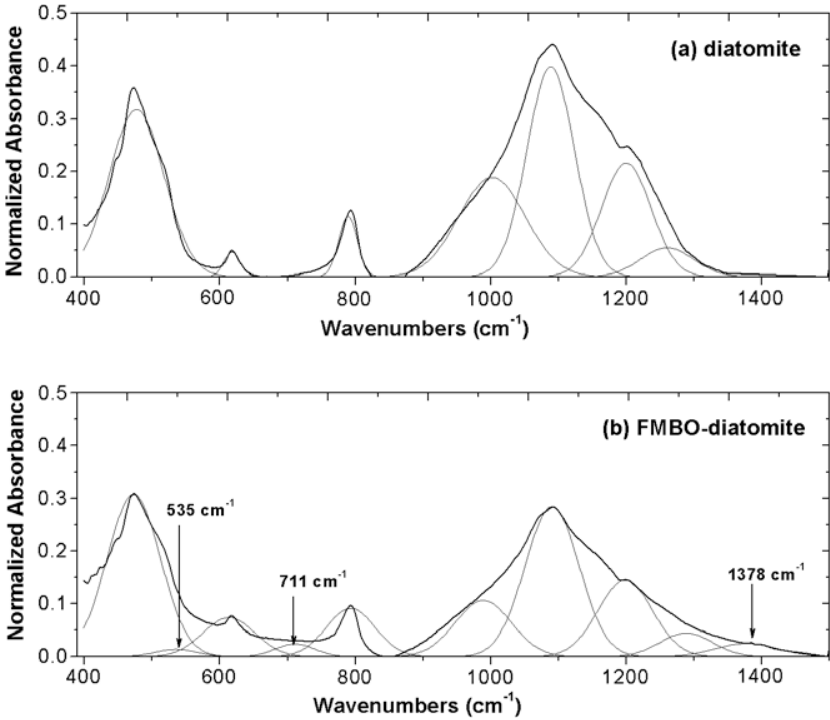

Fig. 2. Partial FTIR spectra and curve fitting of (a) diatomite $\left(r^{2}=0.9452\right)$ and (b) FMBO-diatomite $\left(r^{2}=0.9486\right)$.

stretching bond or the Mn-O vibration bonding [14,15]. The characteristic peak at $1378 \mathrm{~cm}^{-1}$ indicates the $\mathrm{O}-\mathrm{H}$ bending vibrations combined with Mn atoms [15]. The peak at $711 \mathrm{~cm}^{-1}$ was not an infrared characteristic peak of iron oxides and manganese oxides. Kwon et al. [16] affirmed that the peak at $710 \mathrm{~cm}^{-1}$ was the Fe$\mathrm{O}-\mathrm{Si}$ band when $\gamma$-FeOOH particles were incorporated with silicate ions. As a supporting material, diatomite mainly consisted of silicon dioxide. In the preparation of FMBO-diatomite, the diatomite was directly immersed into the $\mathrm{FeSO}_{4}$ solution. It is suggested that the peak at $711 \mathrm{~cm}^{-1}$ in Fig. $2 \mathrm{~b}$ can be assigned to the vibration of the $\mathrm{Fe}-\mathrm{O}-\mathrm{Si}$ bond. These results also indicated that a strong surface complex was formed between Fe-Mn binary oxide and diatomite instead of a simple physical mixture, which is described in Fig. 3. The surface complex can enhance the granulated adsorbent strength [17], and contribute to the high stability of FMBOdiatomite.

\subsubsection{BET surface area analysis}

The adsorption efficiency depended on surface area, surface charge, and pore volume of the adsorbent [18]. After being incorporated by a small amount of Fe-Mn binary oxide which had a high surface area [12], the surface area of diatomite increased $36 \%$ and the porosity was improved significantly (see Table 1). The improved surface characteristics can enhance the As(III) adsorption efficiency, which will be exhibited subsequently.

\subsubsection{Potentiometric titrations}

It is known that the interface of FMBO-diatomite plays an important role in the adsorption process. The quality and the quantity of the surface charges were determined via potentimetric titration analysis. The surface charge $\left(\sigma_{\mathrm{H}}\right)$ was calculated using [19]

$\sigma=\frac{\left(C_{\mathrm{A}}-C_{\mathrm{B}}+\left[\mathrm{OH}^{-}\right]-\left[\mathrm{H}^{+}\right]\right)}{\mathrm{a}} \frac{F}{\mathrm{~s}}$.

In this equation, $\sigma$ is the surface charge $\left(\mathrm{C} / \mathrm{m}^{2}\right) ; C_{\mathrm{A}}$ is the added acid concentration $(\mathrm{mol} / \mathrm{L}) ; C_{\mathrm{B}}$ is the added base concentration $(\mathrm{mol} / \mathrm{L})$; $\left[\mathrm{OH}^{-}\right]$is the hydroxyl ion concentration $(\mathrm{mol} / \mathrm{L}) ;\left[\mathrm{H}^{+}\right]$is the proton concentration ( $\mathrm{mol} / \mathrm{L}) ; a$ is the solid concentration $(\mathrm{g} / \mathrm{L}) ; F$ is the Faraday constant $(96,500 \mathrm{C} / \mathrm{mol})$; and $s$ represents the specific surface area $\left(\mathrm{m}^{2} / \mathrm{g}\right)$.

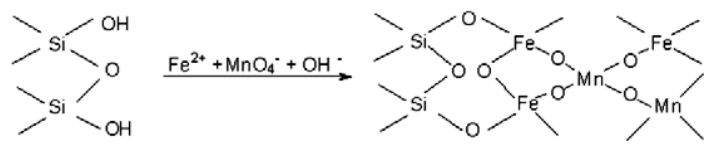

Fig. 3. Schematic bonding for Fe-Mn binary oxide with silicon hydroxyl. 
Table 1

The physical characterization of diatomite and FMBO-diatomite.

\begin{tabular}{llllc}
\hline Sample & $\begin{array}{l}\text { Surface area } \\
\left(\mathrm{m}^{2} / \mathrm{g}\right)\end{array}$ & $\begin{array}{l}\text { Pore volume } \\
(\mathrm{mL} / \mathrm{g})\end{array}$ & $\begin{array}{l}\text { Average pore } \\
\text { diameter }(\AA)\end{array}$ & $\begin{array}{l}\text { Fe and } \mathrm{Mn} \\
\text { content }(\mathrm{mg} / \mathrm{g})\end{array}$ \\
\hline Diatomite & 11.09 & 0.005 & 18.13 & 0.00 \\
FMBO-diatomite & 15.04 & 0.025 & 67.96 & 11.87
\end{tabular}

The calculated surface charges of FMBO-diatomite are shown in Fig. 4. The zero point of charge $\left(\mathrm{pH}_{\mathrm{zpc}}\right)$ of FMBO-diatomite is identified as the common intersection point of three titration curves recorded at different ionic strengths. It is determined to be 8.1. By contrast, the $\mathrm{pH}_{\mathrm{zpc}}$ of diatomite was typically below $\mathrm{pH} 3.0$ because of a permanent structural negative charge caused by $\mathrm{Si}-\mathrm{OH}$ [20].

\subsection{Effect of the temperature on As(III) adsorption isotherms}

The adsorption isotherms, which take into account the effects of equilibrium concentration on the adsorption capacity under different temperatures at pH 5.0 and 7.0, are shown in Fig. 5. The Langmuir isotherm model is used to evaluate the experimental results. In Eq. (2), $q_{\max }$ and $b$ represent the maximum adsorption capacity $(\mathrm{mg} / \mathrm{g})$ and the affinity between the adsorbent and the adsorbate, respectively. In addition, $q_{-}\{\mathrm{e}\}$ is the amount of adsorbate adsorption on the adsorbent $(\mathrm{mg} / \mathrm{g})$, and $C_{-}\{\mathrm{e}\}$ is the equilibrium concentration in the solution $(\mathrm{mg} / \mathrm{L})$. These parameters and $r^{2}$ are shown in Table 2.

$q_{\mathrm{e}}=\frac{q_{\max } b C_{\mathrm{e}}}{1+b C_{\mathrm{e}}}$.

From Table 2, $r^{2}$ values are found to be 0.851-0.982. Being different from Fe-Mn binary oxide [12], the adsorption behavior of FMBO-diatomite was described well by the Langmuir isotherm model, which assumes monolayer adsorption onto a homogeneous surface with a finite number of identical sites [21]. It is suggested that Fe-Mn binary oxide dispersed well on the diatomite as a layer of adsorption sites. In addition, it can be seen from Fig. 5 that the amount of adsorption increases with the initial concentration of As(III) and temperature, and finally reaches saturation.

Specially, at $25^{\circ} \mathrm{C}$ and $\mathrm{pH} 5.0$, the maximum As(III) adsorption capacity of FMBO-diatomite was $1.76 \mathrm{mg} / \mathrm{g}$. Judging from the amount of $\mathrm{Fe}$ and $\mathrm{Mn}$ incorporated into diatomite $(11.9 \mathrm{mg} \mathrm{Fe}$ and $\mathrm{Mn} / \mathrm{g}$ FMBO-diatomite), the maximum adsorption capacity

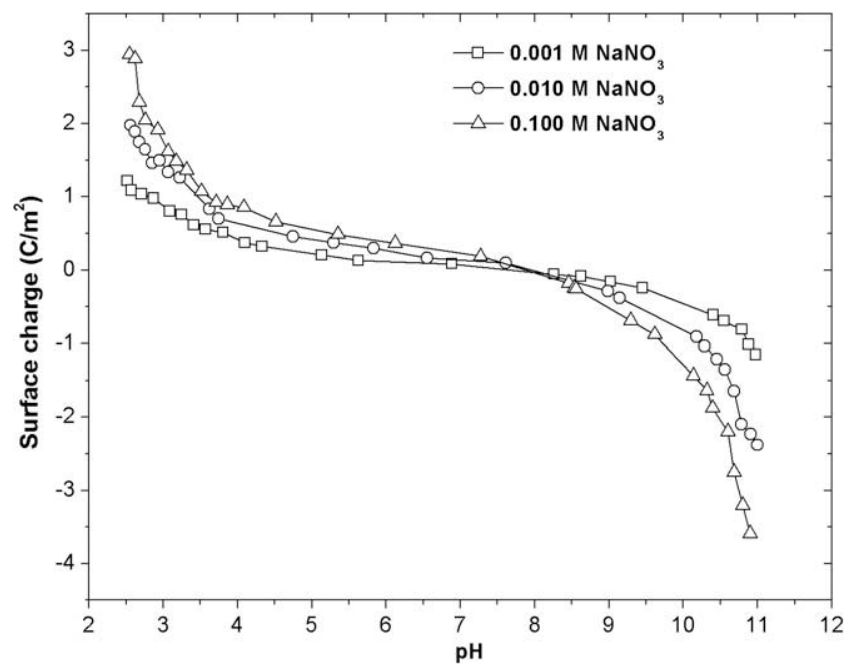

Fig. 4. The surface charge of FMBO-diatomite as a function of $\mathrm{pH}$ at different ionic strengths (solid concentration $1.0 \mathrm{~g} / \mathrm{L}, 25^{\circ} \mathrm{C}$, equilibrium time $24 \mathrm{~h}, \mathrm{~N}_{2}$ gas blow off).
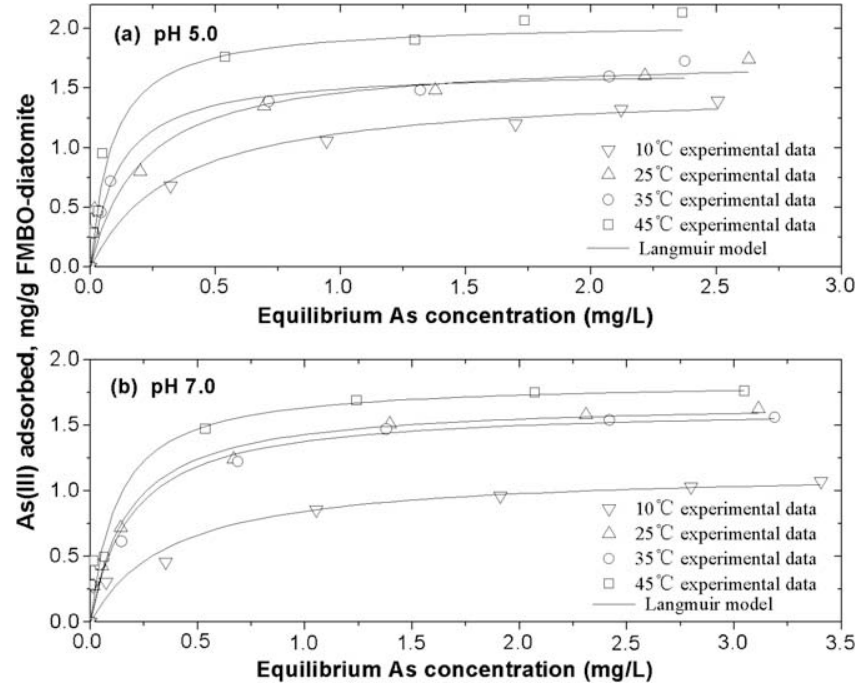

Fig. 5. As(III) adsorption isotherms on FMBO-diatomite at (a) pH 5.0 and (b) pH 7.0 (solid concentration $1.0 \mathrm{~g} / \mathrm{L}$, and equilibrium time $24 \mathrm{~h}$ ).

Table 2

The Langmuir isotherms parameters of As(III) adsorption by FMBO-diatomite at pH 5.0 and 7.0

\begin{tabular}{lllllllll}
\hline Temperature $\left({ }^{\circ} \mathrm{C}\right)$ & $\mathrm{pH} 5.0$ & & & $\mathrm{pH} 7.0$ & & \\
\cline { 2 - 3 } & $q_{\max }(\mathrm{mg} / \mathrm{g})$ & \multicolumn{1}{c}{$b$} & $r^{2}$ & & $q_{\max }(\mathrm{mg} / \mathrm{g})$ & $b$ & $r^{2}$ \\
\hline 10 & 1.51 & 2.91 & 0.851 & & 1.16 & 2.67 & 0.938 \\
25 & 1.76 & 4.87 & 0.922 & & 1.68 & 5.62 & 0.986 \\
35 & 1.66 & 8.94 & 0.982 & & 1.64 & 5.21 & 0.970 \\
45 & 2.06 & 11.67 & 0.964 & & 1.84 & 8.08 & 0.959 \\
\hline
\end{tabular}

can also be calculated to be about $147.9 \mathrm{mg} \mathrm{As(III)/g} \mathrm{Fe} \mathrm{and} \mathrm{Mn,}$ which was higher than that of Fe-Mn binary oxide [12]. The increased adsorption capacity is attributed to the effective utilization of Fe-Mn binary oxide. The obtained maximum adsorption capacity of FMBO-diatomite is compared with those obtained using other low-cost and natural adsorbents in Table 3. These results suggested that FMBO-diatomite loaded with a small amount of Fe-Mn binary oxide was more effective for As(III) removal than other Fe-Mn-based adsorbents.

\subsection{Effect of $\mathrm{pH}$ on As(III) adsorption}

The effect of the initial solution $\mathrm{pH}(2.0-11.0)$ on $\mathrm{As}(\mathrm{III})$ removal is illustrated in Fig. 6. The concentrations of As(tot) and As(III) in the solution were analyzed simultaneously, and $\mathrm{As}(\mathrm{V})$ was calculated by the difference. Increased As(III) and As(tot) concentrations with the $\mathrm{pH}$ in solutions reflected that the oxidation and adsorption efficiencies of $\mathrm{As}(\mathrm{III})$ decreased. In the $\mathrm{pH}$ range of 2.0-11.0, the As(III) oxidation efficiency was higher than the adsorption efficiency. It is proved that $\mathrm{As}(\mathrm{III})$ was oxidized to $\mathrm{As}(\mathrm{V})$, and then the $\mathrm{As}(\mathrm{V})$ was adsorbed onto FMBO-diatomite. The manganese dioxide in Fe-Mn binary oxide may play an important role in the As(III) oxidation [23].

The oxidation of $\mathrm{As}(\mathrm{III})$ to $\mathrm{As}(\mathrm{V})$ undoubtedly promoted the adsorption efficiency, because $\mathrm{As}(\mathrm{V})$ species are negatively charged and $\mathrm{As}(\mathrm{III})$ exists mainly as a neutral molecule in natural water [3]. Decreasing adsorption efficiency with increasing $\mathrm{pH}$ may reflect the declining surface charge of FMBO-diatomite. It is explained that the adsorption behavior was dominated by electrostatic attraction [22]. 
Table 3

Maximum As(III) adsorption capacities of some adsorbents.

\begin{tabular}{|c|c|c|c|c|c|}
\hline Adsorbent & Max. As(III) adsorption capacity (mg/g) & $\mathrm{pH}$ & Temp. $\left({ }^{\circ} \mathrm{C}\right)$ & Con. range (mg/L) & Model used to calculate adsorption capacity \\
\hline FMBO-diatomite (11.87 mg Fe and Mn) & 1.68 & 7.0 & 25 & $0.05-5.0$ & Langmuir \\
\hline Ferruginous manganese ore [6] & 0.5367 & 6.3 & - & - & Langmuir \\
\hline Natural siderite [26] & 1.04 & $\sim 7.0$ & 20 & $0.25-2.0$ & Langmuir \\
\hline Iron oxide-coated sand [27] & 0.998 & $\sim 7.0$ & 25 & $0.7-13.5$ & Langmuir \\
\hline
\end{tabular}

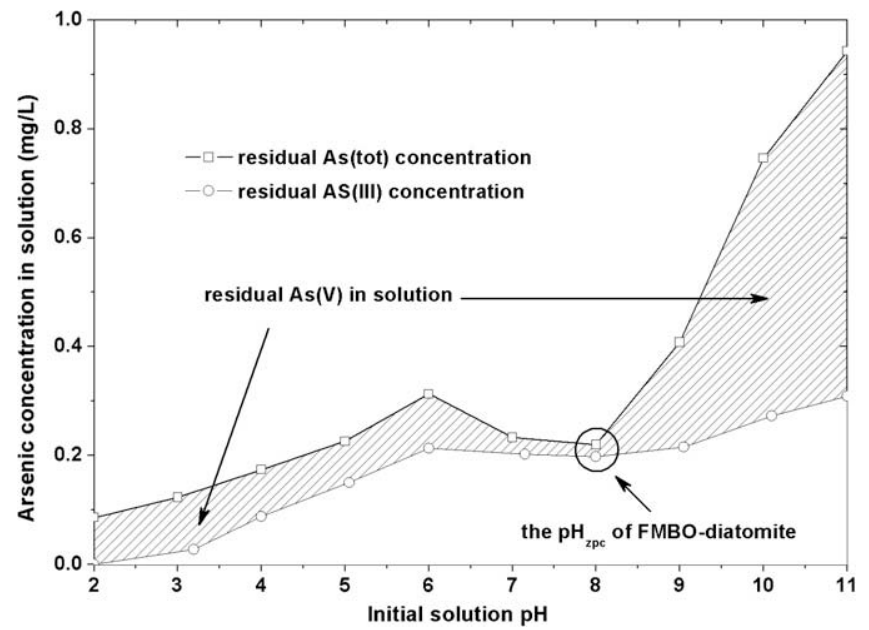

Fig. 6. Effect of initial solution pH on As(III) adsorption by FMBO-diatomite $\left(25^{\circ} \mathrm{C}\right.$, solid concentration $1.0 \mathrm{~g} / \mathrm{L}$, initial As(III) concentration $1.0 \mathrm{mg} / \mathrm{L}$, and equilibrium time $6.0 \mathrm{~h})$.

The lowest residual $\mathrm{As}(\mathrm{V})$ concentration was found around $\mathrm{pH}$ 8.1 which was the $\mathrm{pH}_{\mathrm{zpc}}$ of FMBO-diatomite. Singh et al. [28] observed that specific adsorption caused an increase of adsorption capacity for $\mathrm{As}(\mathrm{V})$ on hematite and feldspar at $\mathrm{pH}_{\mathrm{zpc}}$. In this study, the adsorption efficiency was almost equal to the oxidation efficiency when the $\mathrm{pH}$ was raised to $\mathrm{pH}_{\mathrm{zpc}}$. It is assumed that the specific adsorption is another important mechanism for As(III) removal by FMBO-diatomite.

\subsection{Influence of the coexisting anions}

The influences of coexisting anions, carbonate, sulfate, fluoride, nitrate, silicate, and phosphate on $\mathrm{As}(\mathrm{III})$ adsorption at $\mathrm{pH} 3.5,6.0$, and 9.0 are shown in Fig. 7. It is found that carbonate, sulfate, fluoride, and nitrate had little positive effect on As(III) adsorption. With the addition of these anions, the ionic strength of the solution was increased, which may be responsible for the increase of the adsorption efficiency. The increased ionic strength could make the double layer more compressed and the electrostatic potential that contributed to adsorption became more positive, thus enhancing the adsorption capacity [24]. On the contrary, the presence of silicate and phosphate showed a significantly negative influence on As(III) adsorption. Similar results were reported by Su and Puls [25] and they explained that silicate and phosphate can compete with $\mathrm{As}$ (III) for similar adsorption sites. In the case of As(III) adsorption onto FMBO-diatomite, the negative influence of silicate increased with an increase of $\mathrm{pH}$. With the presence of phosphate, As(III) had slightly higher adsorptive affinity on FMBO-diatomite in alkaline solution than in acid solution. The adsorption efficiency of phosphate onto FMBO-diatomite decreased when the $\mathrm{pH}$ was raised. It is clear that the adsorption of phosphate on FMBO-diatomite depends more deeply on the $\mathrm{pH}$ of solution than the adsorption of As(III).

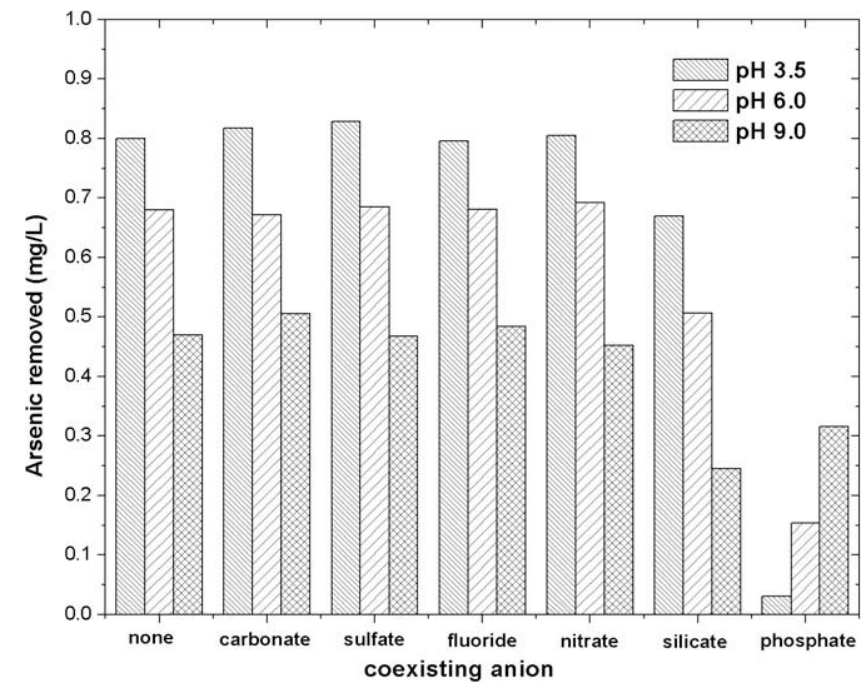

Fig. 7. Effects of coexisting anions on As(III) removal at $\mathrm{pH} 3.5,6.0$, and $9.0\left(25^{\circ} \mathrm{C}\right.$, solid concentration $1.0 \mathrm{~g} / \mathrm{L}$, initial As(III) concentration $1.0 \mathrm{mg} / \mathrm{L}$, coexisting anions concentration $1.0 \mathrm{mmol} / \mathrm{L}$, and equilibrium time $6.0 \mathrm{~h}$ )

\section{Conclusions}

Fe-Mn binary oxide has been homogeneously incorporated into diatomite and exhibited high As(III) removal efficiency. The oxidation of As(III) can significantly enhance the As(III) removal efficiency and reduce the As(III) toxicity. Acid solution and high temperature are advantageous to oxidize and adsorb As(III). Electrostatic attraction and specific adsorption were the two major forces during the As(III) adsorption process. Being different from other coexisting anions, the presence of silicate and phosphate has negative effects on the $\mathrm{As}(\mathrm{III})$ adsorption. With the increase of $\mathrm{pH}$, the negative influence of silicate was enhanced, while the competition ability of phosphate for the adsorption sites was weakened. Because of the high oxidation ability and adsorption capacity for As(III), FMBO-diatomite can be filled into fixed beds for large-scale water treatments, in order to remove As(III) with low concentration from water rapidly and effectively.

\section{Acknowledgments}

The authors gratefully acknowledge the generous financial support of this work by National Natural Science Foundation of China (Grant 50608067) and Creative Research Groups of China (Grant 50621804).

\section{References}

[1] J. Matschullat, Sci. Total Environ. 249 (2000) 297.

[2] T.S.Y. Choong, T.G. Chuah, Y. Robiah, F.L. Gregory Koay, I. Azni, Desalination 217 (2007) 139.

[3] P.L. Smedley, D.G. Kinniburgh, Appl. Geochem. 17 (2002) 517.

[4] EPA 815-P-01-001, Technologies and Costs for Removal of Arsenic from Drinking Water, Washington, DC, 1999.

[5] D. Mohan, C.U. Pittman Jr., J. Hazard. Mater. 142 (2007) 1. 
[6] S. Chakravarty, V. Dureja, G. Bhattacharyya, S. Maity, S. Bhattacharjee, Water Res. 36 (2002) 625.

[7] P. Lakshmipathiraj, B.R.V. Narasimhan, S. Prabhakar, G. Bhaskar Raju, J. Colloid Interface Sci. 304 (2006) 317.

[8] M.A. Al-Ghouti, M.A.M. Khraisheh, S.J. Allen, M.N. Ahmad, J. Environ. Manage. 69 (2003) 229.

[9] Y. Al-Degs, M.A.M. Khraisheh, M.F. Tutunji, Water Res. 35 (2001) 3724.

[10] M.A. Al-Ghouti, M.A.M. Khraisheh, M.N. Ahmad, S.J. Allen, J. Hazard. Mater. 146 (2007) 316.

[11] M. Jang, S.H. Min, T.H. Kim, J.K. Park, Environ. Sci. Technol. 40 (2006) 1636.

[12] G.S. Zhang, J.H. Qu, H.J. Liu, R.P. Liu, R.C. Wu, Water Res. 41 (2007) 1921.

[13] B. Bahramian, F.D. Ardejani, V. Mirkhani, K. Badii, Appl. Catal. A 345 (2008) 97.

[14] S.A. Kahni, M. Jafari, J. Magn. Magn. Mater. 321 (2009) 1951.

[15] S. Senthilkumaar, K. Rajendran, S. Banerjee, T.K. Chini, V. Sengodan, Mater. Sci. Semicond. Process. 11 (2008) 6.
[16] S.K. Kwon, K. Shinoda, S. Suzuki, Y. Waseda, Corros. Sci. 49 (2007) 1513.

[17] L. Zeng, Water Res. 37 (2003) 4351.

[18] R.M. Cornell, U. Schwertmann, VCH, New York, 1983, p. 265.

[19] W. Stumm, Wiley, New York, 1992, p. 16.

[20] B.A. Manning, S. Goldberg, Environ. Sci. Technol. 31 (1997) 2005.

[21] M.P. Elizalde-Gonzalez, J. Mattusch, R. Wennrich, P. Morgenstern, Microporous Mesoporous Mater 46 (2001) 277.

[22] C.M. Su, R.W. Puls, Environ. Sci. Technol. 35 (2001) 1487.

[23] G.S. Zhang, J.H. Qu, H.J. Liu, R.P. Liu, G.T. Li, Environ. Sci. Technol. 41 (2007) 4613.

[24] Q. Du, Z.X. Sun, W. Forsling, H. Tang, J. Colloid Interface Sci. 187 (1997) 232.

[25] C.M. Su, R.W. Puls, Environ. Sci. Technol. 35 (2001) 4562.

[26] H.M. Guo, D. Stuben, Z. Berner, J. Colloid Interface Sci. 315 (2007) 47.

[27] S. Kundu, A.K. Gupta, Chem. Eng. J. 122 (2006) 93.

[28] D.B. Singh, G. Prasad, D.C. Rupainwar, Colloids Surf., A 111 (1996) 49. 